\title{
Spontaneous abortions among dental assistants, factory workers, painters, and gardening workers: a follow up study
}

\author{
LENE ZEUTHEN HEIDAM \\ From the Institute of Community Health, Department of Social Medicine, Odense University, 5000 Odense C, \\ Denmark
}

SUMMARY This investigation was conducted to test the hypothesis that exposure of pregnant women to chemicals increáses the risk of spontaneous abortion. The chemical risk factors under study to which dental assistants, factory workers, painters, and gardening workers were exposed were nitrous oxide, inorganic mercury, organic solvents, and pesticides. The study was carried out within the Danish county of Funen. It included all dental assistants employed in private or public dentistry. A comparable reference group was made up by employees less exposed to chemicals. Further study groups included all women painters within the county, women factory workers from selected factories, and about $50 \%$ of the women gardening workers within the county. Shop assistants and packers formed their control group. Information was obtained through a postal questionnaire study in May 1980 and from hospital records. Only among factory workers and painters was the odds ratio of spontaneous abortion found to be significantly increased. Neither among these women nor among dental assistants and gardening workers, however, was the reported exposure to any single chemical during pregnancy associated with a significantly increased odds ratio of spontaneous abortion.

The widespread occupational use of chemicals, the susceptibility of the rapidly dividing germ cells and the developing fetus, the few restrictions imposed when new chemicals are introduced in industry, and our lack of knowledge emphasise the importance of examining the effect of occupational chemical exposure on human reproduction.

Organic solvents constitute a category of substances used extensively in industry, and nitrous oxide is a commonly used anaesthetic. In vitro and in vivo studies in animals indicate that these chemicals may have embryotoxic or fetotoxic effects. ${ }^{1}$ Halogenated organic solvents are chemically related to anaesthetic gases, and epidemiological investigations suggest that an occupational environment involving anaesthetics may influence the reproductive capacity of operating room personnel. ${ }^{1-3}$

A high risk of malformations of the central nervous system among children of mothers exposed to organic solvents during the first trimester of pregnancy has been found. ${ }^{4}$ It has been suggested that these findings were due to information bias, ${ }^{5}$ and they were not confirmed when the exposure status was based on more objective but less precise occupational titles. ${ }^{6}$ No effect on the risk of spontaneous abortions was seen in studies among laboratory workers exposed to organic solvents..$^{7.8}$

Dental assistants exposed to nitrous oxide during pregnancy and wives of exposed dentists were shown to have a high risk of spontaneous abortions and the risk increased. with the intensity of exposure. ${ }^{9}$ Nevertheless, the reply rates were below $74 \%$.

Both organic and inorganic mercury have been shown to be embryotoxic in studies on animals, ${ }^{10}$ but only exposure of pregnant women to methylmercury is known to carry excess risk to the fetus. ${ }^{1}$ Occupationally low exposure to inorganic mercury has, however, been shown to induce aneuploidy. ${ }^{11}$ Inorganic mercury poisoning may lead to abortions. ${ }^{12}$

Studies in animals have shown that pesticides as a group are embryotoxic only at high doses. ${ }^{13}$ Heavy exposure of men to DBCP was associated with 
infertility due to azospermia or oligospermia, ${ }^{14}$ and low sperm counts have been found in those less exposed to DBCP. ${ }^{15}$ A Danish study found that the risk of male or female infertility was not associated either with occupations involving pesticide application or with specific pesticide exposure at work. ${ }^{16}$ It has been suggested in a register study that women working in agriculture may be at higher risk of spontaneous abortions compared with all women, ${ }^{17}$ but the method used was imprecise.

Carcinogens must be considered a hazard to the developing embryo if they cross the placental barrier. ${ }^{1}$

The present study investigates different female occupations and occupational chemical exposures as risk factors for spontaneous abortions. The exposures are nitrous oxide and inorganic mercury by dental assistants, organic solvents by factory workers and painters, and pesticides by gardening workers. The risk of spontaneous abortion is estimated using data from a questionnaire and hospital register.

\section{Subjects and methods}

\section{QUESTIONNAIRE STUDY}

The investigation is based on data from a historical prospective study of women representing 12 selected occupations within the Danish county of Funen (population about 430000 ). The eligibility of subjects to the study and the collection of questionnaire data have been previously described in detail. ${ }^{8}$ Data were collected covering the women's entire reproductive life before May 1980.

\section{Study subjects}

This investigation deals with 10 of the 12 occupations. Dental assistants worked in private dental clinics or in dental schoolservices. Many of these were exposed to nitrous oxide and according to the heads of the clinics often worked in poorly ventilated clinics. Furthermore, exposure to inorganic mercury in amalgan by inhalation or skin contact was common. Their control group were employees less exposed to chemicals at work and included physiotherapists, occupational therapists, office workers, and technical assistants and designers. The study group and the controls were comparable with respect both to work postures and movements during a day. A few office workers, however, who handled parcels in post offices and physiotherapists who treated patients were probably exposed to greater physical strain than were the study group.

Factory workers were predominantly exposed to organic solvents in the rubber, plastics, machines, and tin industries. Painters were all exposed to organic solvents and may also have been exposed to potential teratogens such as phthalic acid esters ${ }^{13}$ and potential mutagens such as epoxies ${ }^{1}$ in waterbased paints. Most of the painting work was done indoors. Sometimes protective equipment was used.

Many gardening workers were exposed to pesticides and most work was done in greenhouses. The exposure by spraying was probably intense, but only skilled gardeners were authorised to spray and they made up only $9 \%$ of the group. Indoors the unskilled gardeners might be indirectly exposed on the day after the spraying. Their controls were shop assistants from larger supermarkets and packers from a packing warehouse for vegetables who were less exposed to chemicals at work, and who were considered to be of similar socioeconomic status to the gardeners, painters, and factory workers. Furthermore the factory workers and the reference group were comparable both for work postures which were either sitting or standing for a long time and for physical strain, since minor subgroups among all these workers undertook heavy lifting. The gardening workers and the painters, however, probably changed work postures more frequently than did the control group.

\section{Sampling}

Within the county there are 24 clinics for the dental schoolservice and 194 private dental clinics, including clinics closed down after 1973. All dental schoolservice clinics and 186 private clinics helped in the study. Five clinics refused to submit the information on the assistants who had left work (about 15 women). Sampling of the reference group of employees has been described previously. ${ }^{8}$ One hospital and one factory did not supply the information on employees who had left work (about 10 women) and two women refused from the start to be included in the study.

The criteria for entrance into the study of a factory were size and direct or indirect exposure of many female factory workers to organic solvents as reported by the factory inspectors. All six factories who were asked to help in the study complied. The painters were selected from every local division of the trade union. The gardening workers were members of the Odense division of a trade union that includes about $50 \%$ of the members within the county. Of 24 supermarkets who were asked to help in the study, 19 , covering $91 \%$ of the employees, complied. Five supermarkets did not submit the information on shop assistants no longer employed (about 60 women). From three of the largest supermarkets the information on formerly employed shop assistants was not given until these had agreed to enter the study, and 305 of the 317 women agreed. The 
packing warehouse for vegetables in Odense also participated in the study as a reference group. The information on packers who had left the job, however, was missing for about 10 women. In summary, owing to insufficient information from the participating employers, about 110 women, covering less than $2 \%$ of the subjects eligible for the study, were not included. Table 1 presents the response rates among the occupational groups.

Table 1 Response rates to postal questionnaires

\begin{tabular}{lcccc}
\hline & \multicolumn{2}{c}{$\begin{array}{c}\text { Questionnaires } \\
\text { sent }\end{array}$} & & \multicolumn{2}{c}{ Replies received } \\
\cline { 2 - 2 } \cline { 5 - 5 } Group of women & No & & No & $\%$ \\
\hline Dental assistants & 772 & & 728 & 94 \\
Reference group employees & 1571 & & 1431 & 91 \\
Factory workers & 1431 & & 1203 & 85 \\
Gardening workers & 965 & & 853 & 88 \\
Painters & 81 & & 76 & 94 \\
Reference group workers & 1034 & & 914 & 88 \\
\hline
\end{tabular}

We have previously described the methods of analysis of the questionnaire data, the calculation of the spontaneous abortion rate, and the odds ratio (OR), the risk estimate of spontaneous abortion. ${ }^{8}$
HOSPITAL STUDY

A description of the hospital data and the methods of analysis has been given. ${ }^{8}$ Respondents and non-respondents to the questionnaire were all examined for abortions and births that occured in the county of Funen. All women except 11 dental assistants provided their civil identification number which ensured complete follow up in the hospital data.

\section{Results}

QUESTIONNAIRE STUDY

Table 2 shows the crude odds ratios of spontaneous abortion by occupation using questionnaire data only; these tend to be increased for factory workers, painters, and outdoor gardening workers. Only factory workers, however, had a statistically significant increased $O R$ of $1.9 \quad(p<0.05)$. Controlling for gravidity, pregnancy order, and the woman's age at pregnancy using a logistic regression model did not change any of the ORs substantially, except the OR of 2.0 for painters, which increased to 2.9 and became borderline statistically significant.

Table 3 shows the ORs for spontaneous abortion within selected groups according to whether the women reported exposure to chemicals or not. Women who did not know whether they were exposed and those who did not reply were regarded as not exposed. Overall, $5 \%$ of women did not know whether they were exposed and $15 \%$ did not reply.

Table 2 Odds ratio of self reported spontaneous abortion among women who worked in chemically exposed occupations during pregnancy compared with women who worked in a reference occupation during pregnancy (95\% confidence interval)

\begin{tabular}{|c|c|c|c|c|c|c|}
\hline \multirow[b]{2}{*}{ Occupation } & \multirow{2}{*}{$\begin{array}{l}\text { Pregnancy } \\
\text { No }\end{array}$} & \multicolumn{2}{|c|}{$\begin{array}{l}\text { Spontaneous } \\
\text { abortions }\end{array}$} & \multirow{2}{*}{$\begin{array}{l}\text { Births } \\
\text { No }\end{array}$} & \multicolumn{2}{|l|}{ Odds ratio } \\
\hline & & No & $\%$ & & Crude & Controlled* \\
\hline Reference group, employees & 843 & 84 & $10 \cdot 0$ & 759 & $1 \cdot 0$ & $1 \cdot 0$ \\
\hline $\begin{array}{l}\text { Dental assistants, } \\
\text { private clinics }\end{array}$ & 259 & 29 & $11 \cdot 2$ & 230 & $\begin{array}{c}1 \cdot 1 \\
(0 \cdot 7-1 \cdot 8)\end{array}$ & $\begin{array}{c}1 \cdot 0 \\
(0 \cdot 6-1 \cdot 6)\end{array}$ \\
\hline $\begin{array}{l}\text { Dental assistants, } \\
\text { dental schoolservice }\end{array}$ & 93 & 9 & $9 \cdot 7$ & 84 & $\begin{array}{c}1 \cdot 0 \\
(0 \cdot 4-2 \cdot 0)\end{array}$ & $\begin{array}{c}0.9 \\
(0.4-2.0)\end{array}$ \\
\hline Reference group workers & 337 & 24 & $7 \cdot 1$ & 313 & $1 \cdot 0$ & $1 \cdot 0$ \\
\hline Factory workers & 357 & 46 & $12 \cdot 9$ & 311 & $\begin{array}{c}1 \cdot 9 \\
(1 \cdot 1-3 \cdot 4)\end{array}$ & $\begin{array}{c}1 \cdot 7 \\
(1 \cdot 0-2 \cdot 9)\end{array}$ \\
\hline Painters & 38 & 5 & $13 \cdot 2$ & 33 & $\begin{array}{c}2 \cdot 0 \\
(0 \cdot 6-5 \cdot 8)\end{array}$ & $\begin{array}{c}2 \cdot 9 \\
(1 \cdot 0-8 \cdot 8)\end{array}$ \\
\hline $\begin{array}{l}\text { Gardening workers, } \\
\text { indoor }\end{array}$ & 102 & 8 & $7 \cdot 8$ & 94 & $\begin{array}{c}1 \cdot 1 \\
(0 \cdot 4-2 \cdot 7)\end{array}$ & $\begin{array}{c}0.9 \\
(0 \cdot 4-2 \cdot 2)\end{array}$ \\
\hline $\begin{array}{l}\text { Gardening workers, } \\
\text { outdoor }\end{array}$ & 18 & 2 & $11 \cdot 1$ & 16 & $\begin{array}{c}1 \cdot 6 \\
(0 \cdot 2-7 \cdot 6)\end{array}$ & $\begin{array}{c}1 \cdot 3 \\
(0 \cdot 2-7 \cdot 1)\end{array}$ \\
\hline
\end{tabular}

*Controlled for gravidity, pregnancy order, and age by logistic regression model. 
Women in most of the exposure categories had no pregnancy order, and age at pregnancy showed increased risk of spontaneous abortion. None of the raised crude ORs were statistically significant. Subsequent analyses using logistic regression to essentially the same results. control for the possible effects of gravidity,

HOSPITAL STUDY

The crude ORs of spontaneous abortions among the

Table 3 Odds ratio of self reported spontaneous abortion among women occupationally exposed to a specific chemical during pregnancy compared with women not exposed to that chemical (95\% confidence interval)

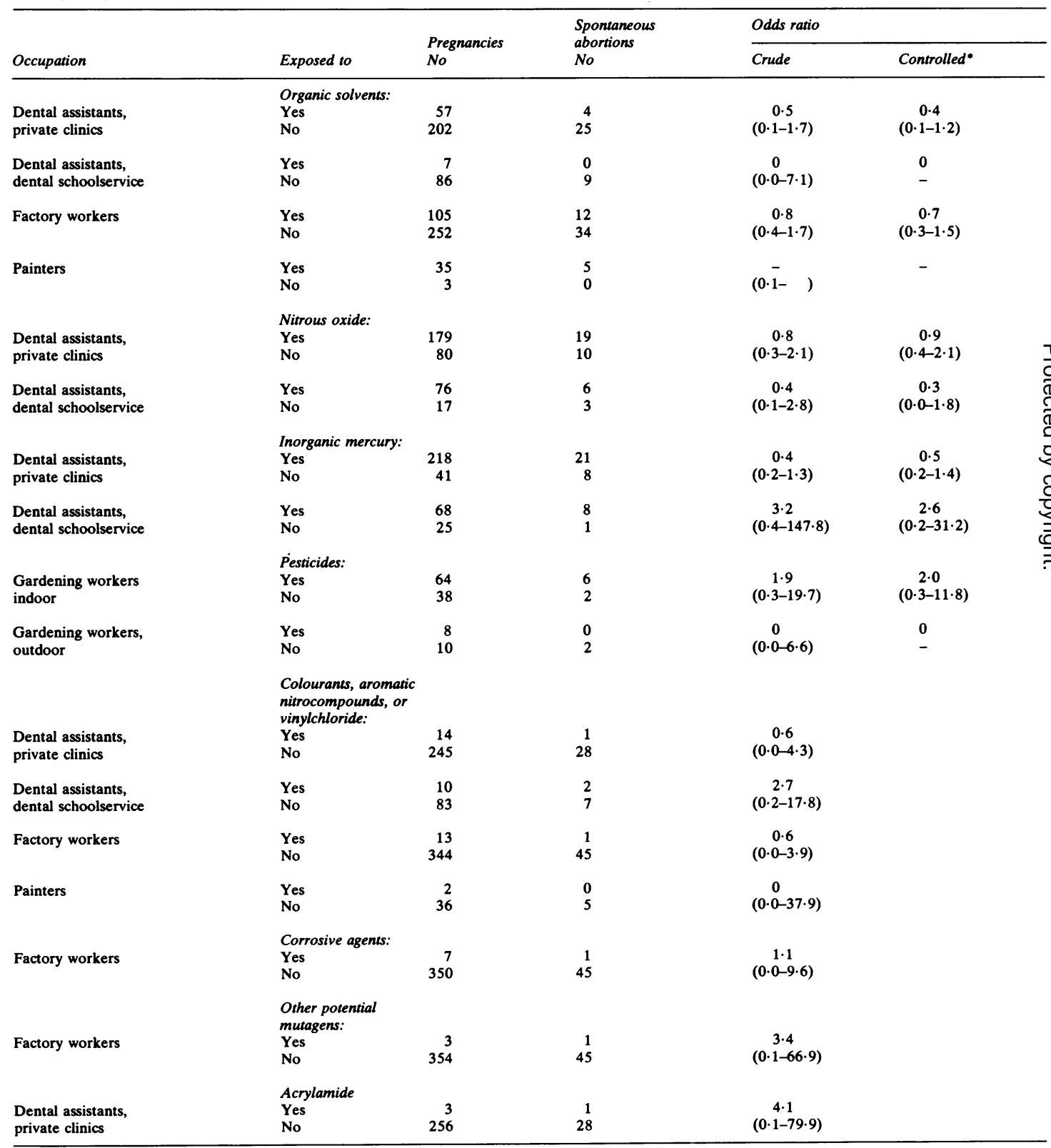

*Controlled for gravidity, pregnancy order, and age by logistic regression model. 
respondents to the questionnarire tend to be increased only for factory workers but this increase is not statistically significant $(p>0.05)$ (table 4$)$. The table shows a trend toward higher rates of spontaneous abortions among the non-respondents in the questionnaire study in comparison with the respondents, except among painters and gardening workers where the opposite is found. None of the differences, however, were significant ( $p>0 \cdot 05)$. For respondents and non-respondents together the ORs are essentially unchanged. But when the ORs are adjusted for age at pregnancy the OR for factory workers increases from 1.3 to 1.4 which is just statistically significant $(\mathrm{p}<0.05)$.

The seeking of care at spontaneous abortion is estimated by ORs of self reported versus hospital abortions (table 5). All groups have raised ORs except dental assistants and painters.

The crude ORs of self reported spontaneous abortions analysed by the woman's occupational title at inclusion in the study is for dental assistants $1 \cdot 0$ $(0 \cdot 8-1 \cdot 2)$ and for gardening workers $1 \cdot 1(0 \cdot 8-1 \cdot 6)$ and are similar to the crude ORs in table 2 . The corresponding ORs for factory workers $1 \cdot 3(1 \cdot 0-1 \cdot 8)$ and for painters $0 \cdot 7(0 \cdot 4-1 \cdot 4)$ are lower than the ORs in table 2. Control for age at pregnancy left ORs unchanged.

\section{Discussion.}

This is one of the first studies of the risk of spontaneous abortion among women exposed to

Table 4 Odds ratio of hospital registered spontaneous abortion in the exposed occupations compared with the reference group among respondents and non-respondents (95\% confidence interval)

\begin{tabular}{|c|c|c|c|c|c|}
\hline \multirow[b]{2}{*}{ Occupation } & \multirow{2}{*}{$\begin{array}{l}\text { Pregnancies } \\
\mathrm{No}\end{array}$} & \multirow{2}{*}{$\begin{array}{l}\text { Spontaneous } \\
\text { abortions } \\
\text { No }\end{array}$} & \multirow[b]{2}{*}{$\%$} & \multicolumn{2}{|l|}{ Odds ratio } \\
\hline & & & & Crude & Controlled* \\
\hline $\begin{array}{l}\text { Respondents: } \\
\text { Reference group employees }\end{array}$ & 921 & 95 & $10 \cdot 3$ & 1.0 & $1 \cdot 0$ \\
\hline Dental assistants & 429 & 49 & $11 \cdot 4$ & $\begin{array}{c}1 \cdot 1 \\
(0 \cdot 7-1 \cdot 7)\end{array}$ & $\begin{array}{c}1 \cdot 0 \\
(0 \cdot 7-1 \cdot 5)\end{array}$ \\
\hline Reference group workers & 445 & 45 & $10 \cdot 1$ & 1.0 & 1.0 \\
\hline Factory workers & 817 & 105 & $12 \cdot 9$ & $\begin{array}{c}1.3 \\
(0.9-1 \cdot 9)\end{array}$ & $\begin{array}{c}1 \cdot 3 \\
(0.9-1.9)\end{array}$ \\
\hline Painters & 48 & 5 & $10 \cdot 4$ & $\begin{array}{c}1 \cdot 0 \\
(0 \cdot 4-3 \cdot 3)\end{array}$ & $\begin{array}{c}1 \cdot 1 \\
(0 \cdot 4-2 \cdot 9)\end{array}$ \\
\hline Gardening workers & 518 & 59 & $11 \cdot 4$ & $\begin{array}{c}1 \cdot 1 \\
(0 \cdot 7-1 \cdot 9)\end{array}$ & $\begin{array}{c}1 \cdot 2 \\
(0 \cdot 8-1 \cdot 8)\end{array}$ \\
\hline $\begin{array}{l}\text { Non respondents: } \\
\text { Reference group employees }\end{array}$ & 67 & 11 & $16 \cdot 4$ & & \\
\hline Dental assistants & 20 & 3 & 15.0 & & \\
\hline Reference group workers & 44 & 6 & 13.6 & & \\
\hline Factory workers & 129 & 23 & $17 \cdot 8$ & & \\
\hline Painters & 6 & $\mathbf{0}$ & 0 & & \\
\hline Gardening workers & 56 & 4 & $7 \cdot 1$ & & \\
\hline $\begin{array}{l}\text { Total: } \\
\text { Reference group employees }\end{array}$ & 988 & 106 & $10 \cdot 7$ & 1.0 & 1.0 \\
\hline Dental assistants & 449 & 52 & 11.6 & $\begin{array}{c}1 \cdot 1 \\
(0 \cdot 7-1 \cdot 7)\end{array}$ & $\begin{array}{c}1 \cdot 2 \\
(0 \cdot 8-1 \cdot 7)\end{array}$ \\
\hline Reference group workers & 489 & 51 & 10.4 & 1.0 & 1.0 \\
\hline Factory workers & 946 & 128 & $13 \cdot 5$ & $\begin{array}{c}1 \cdot 3 \\
(0 \cdot 9-1 \cdot 9)\end{array}$ & $\begin{array}{c}1 \cdot 4 \\
(1 \cdot 0-1 \cdot 9)\end{array}$ \\
\hline Painters & 54 & 5 & $9 \cdot 3$ & $\begin{array}{c}0 \cdot 9 \\
(0 \cdot 3-2 \cdot 3)\end{array}$ & $\begin{array}{c}1.4 \\
(0.4-2 \cdot 5)\end{array}$ \\
\hline Gardening workers & 574 & 63 & 11.0 & $\begin{array}{c}1 \cdot 1 \\
(0 \cdot 6-1 \cdot 9)\end{array}$ & $\begin{array}{c}1 \cdot 1 \\
(0 \cdot 7-1 \cdot 6)\end{array}$ \\
\hline
\end{tabular}

"Controlled for age. 
painting work, gardening work, inorganic mercury in dentistry, and organic solvents in factories.

The data do not indicate a general increased risk of spontaneous abortions among dental assistants or gardening workers. In none of the categories of dental clinics or gardening work are women at an enhanced risk of spontaneous abortion. The negative findings are probably not due to raised risk among controls, since their rates of hospital abortions $10.7 \%$ and $10.4 \%$ are below the rate of $12 \%$ in the Danish population. ${ }^{18}$ The risk of spontaneous abortion among factory workers was, on the other hand, significantly raised. In addition to the chemical exposure, however, these women are exposed to noise at work or two shift work. Noise was found embryotoxic in animal studies ${ }^{16}{ }^{19}$ and was associated with infertility in women. ${ }^{16}$ Shiftwork has been shown to increase the risk of spontaneous abortions. ${ }^{7}$ The OR was statistically significantly increased among painters, though the sample size was small (table 2). Nevertheless, there is probably information bias among painters and the results were not confirmed by the hospital data and the second set of self reported data (tables 4 and 5).
The information on chemical exposure is not precise, and the intensity and time of exposure in the pregnancy is unknown. The exposure specific ORs below 1 indicate, however, that the exposures probably do not increase the risk of spontaneous abortion, or that only minor subgroups might run a high risk. The negative findings by exposure to organic solvents are similar to those in two studies among laboratory employees. ${ }^{78}$ The exposure specific increased ORs are inexactly estimated owing to the small number of observations. In conclusion, therefore, it cannot be ruled out that some occupational processes involving extensive exposure of women may be dangerous to the embryo.

\section{Bias related to non-response}

The statistically insignificant selection of non-respondents was probably due to their small number, The selection among painters, gardening workers, and their controls tend to exaggerate the ORs among the respondents. Correction of the bias hardly reduced the ORs, probably because the non-respondents were few. The higher spontaneous abortions rate among non-respondent factory

Table 5 Odds ratio of self reported spontaneous abortions compared with hospital registered spontaneous abortions among respondents

\begin{tabular}{|c|c|c|c|c|}
\hline \multirow[b]{2}{*}{ Occupations } & \multirow{2}{*}{$\begin{array}{l}\text { Pregnancies } \\
\text { No }\end{array}$} & \multicolumn{2}{|c|}{ Spontaneous abortions } & \multirow{2}{*}{$\begin{array}{l}\text { Odds ratio } \\
\text { Crude }\end{array}$} \\
\hline & & No & $\%$ & \\
\hline $\begin{array}{l}\text { Self reported: } \\
\text { Reference group employees }\end{array}$ & 1329 & 167 & $12 \cdot 6$ & $\begin{array}{c}1 \cdot 3 \\
(1 \cdot 0-1 \cdot 7)\end{array}$ \\
\hline Dental assistants & 569 & 69 & $12 \cdot 1$ & $\begin{array}{c}1 \cdot 1 \\
(0 \cdot 6-1 \cdot 9)\end{array}$ \\
\hline Reference group workers & 621 & 78 & $12 \cdot 6$ & $\begin{array}{c}1 \cdot 3 \\
(0 \cdot 8-2 \cdot 0)\end{array}$ \\
\hline Factory workers & 1204 & 192 & $15 \cdot 9$ & $\begin{array}{c}1 \cdot 3 \\
(1 \cdot 0-1 \cdot 7)\end{array}$ \\
\hline Painters & 65 & 6 & $9 \cdot 2$ & $\begin{array}{c}0.9 \\
(0.6-1 \cdot 4)\end{array}$ \\
\hline Gardening workers & 741 & 103 & 13.9 & $\begin{array}{c}1 \cdot 3 \\
(0 \cdot 9-1 \cdot 8)\end{array}$ \\
\hline $\begin{array}{l}\text { Hospital registered: } \\
\text { Reference group employees }\end{array}$ & 921 & 95 & $10 \cdot 3$ & \\
\hline Dental assistants & 429 & 49 & $11 \cdot 4$ & \\
\hline Reference group workers & 445 & 45 & $10 \cdot 1$ & \\
\hline Factory workers & 817 & 105 & $12 \cdot 9$ & \\
\hline Painters & 48 & 5 & $10 \cdot 4$ & \\
\hline Gardening workers & 518 & 59 & $11 \cdot 4$ & \\
\hline
\end{tabular}

The fewer hospital registered pregnancies compared with self reported pregnancies is due to two factors: only pregnancies registered at the hospitals within the county of Funen are inlcuded and the register period is one year shorter, 1973 to mid-1980, than the period of self reported pregnancies, 1972 to mid-1980. 
workers than among respondents was unexpected and may reflect that they do not connect the risk of spontaneous abortion with the exposures at work. The uniform selection among the non-respondent factory workers and control imply non-bias.

Bias of questionnaire information or of hospital data The significantly increased OR of self reported versus hospital spontaneous abortions among controls but not among dental assistants, indicates negative information bias. Similar findings were seen in a study of laboratory workers ${ }^{8}$ and in both investigations a medical insight in the study groups may lead to their seeking more frequent care, especially for early abortions, than controls. This would bias the hospital data towards too high ORs of spontaneous abortions. The corresponding ORs are 1.3 within all other occupations (except in painters, whose numbers were few) which do not suggest bias either of self reported or of hospital data.

\section{Discrepencies between different self reported data}

The higher ORs in table 2 of factory workers and painters compared with the ORs analysed by the woman's occupational title could reflect that relatively many index women were not working in the risk occupation while pregnant. ORs in the latter analysis and ORs assessed by hospital data may then be underestimated. The findings indicate that occupational rather than social factors contribute to the increased ORs in the two study groups.

\section{Bias related to induced abortions}

The rate of induced abortion estimated by hospital data among respondent dental assistants is $10 \cdot 1 \%$ (48 of 477 pregnancies) and similar to controls' $9.5 \%$ $(97 / 1018)$. The rates among factory workers $18.9 \%$ (191/1008) and painters $15 \cdot 8 \%(9 / 57)$ are slightly raised compared with controls'13.7\% (72/527), signifying that the ORs assessed by hospital data are a little overestimated. Among gardening workers the rate $12 \cdot 6 \%(75 / 593)$ is lower than among controls, and therefore $O R$ is slightly underestimated.

Induced abortions were sought in the hospital register only when the respondents reported at least one pregnancy after 1972, but they were sought among all non-respondents. Therefore the induced abortions were not included in the analysis of non-response bias.

Whether the association found between factory work, especially painting work, and spontaneous abortion is of an aetiological nature ought to be further examined.

\section{References}

${ }^{1}$ Heidam LZ. Fetotoxicity and chemicals in the occupational environment: a literature review. University of Odense, 1978: 157. (In Danish.)

${ }^{2}$ Tomlin PJ. Health problems of anaesthetists and their families in the West Midlands. Br Med J 1979; i: 779-84.

${ }^{3}$ Axelsson G, Rylander R. Exposure to anaesthetic gases and spontaneous abortions: response bias in a postal questionnaire study. Int J Epidemiol 1982; 11: 250-6.

${ }^{4}$ Holmberg PC. Central-nervous-system defects in children born to mothers exposed to organic solvents during pregnancy. Lancet 1979; ii: 177-9.

${ }^{5}$ Sheik HK. Teratogenic effects of organic solvents. Lancet 1979; ii; 963.

'Holmberg PC, Hernberg S. Congenital defects and occupational factors. A comparison of different methodological approaches. Scand J Work Environ Health 1979; 5: 328-32.

'Axelsson G, Lütz C, Rylander R. Exposure to solvents and pregnancy outcome among university laboratory employees. $\mathrm{Br} J$ Ind $\mathrm{Med}$ (in press).

- Heidam LZ. Spontaneous abortions among laboratory workers; a follow up study. J Epidemiol Community Health 1984; 38: 36-41.

' Cohen EN, Brown BW, Wu ML, et al. Occupational disease in dentistry and chronic exposure to trace anesthetic gases. J Am Dent Asoc 1980; 101: 21-31.

${ }^{10}$ Rizzo AM, Furst A. Mercury teratogenesis in the rat. Proc West Pharmacol Soc 1972; 15: 52-4.

${ }^{11}$ Vershaeve L, Kirsch-Volders M, Susanne C, et al. Genetic damage induced by occupationally low mercury exposure. Environ Res 1976; 12: 306-16.

${ }^{12}$ Friberg L, Vostal J. Mercury in the environment. Cleveland: CRC Press, 1972.

${ }^{13}$ Wilson JG. Environmental chemicals. In: Wilson JG, Fraser FC, eds. Handbook of teratology 1, General principles and etiology. New York and London. Plenum Press, 1977.

${ }^{14}$ Whorton $D$. Infertility in male pesticide workers. Lancet 1977; ii: $1259-61$.

${ }^{15}$ Glass RI, Lyness RN, Mengle DC, Powell KE, Kahn E. Sperm count depression in pesticide applicators exposed to dibromochloropropane. Am J Epidemiol 1979; 109: 346-51.

${ }^{16}$ Rachootin P, Olsen J. The risk of infertility and delayed conception associated with exposures in the Danish workplaces. JOM 1983; 25: 394-402.

${ }^{17}$ Hemminki K, Saloniemi I, Luoma K, et al. Transplacental carcinogens and mutagens: childhhood cancer, malformations and abortions as risk indicators. $J$ Toxicol Environ Health 1980; 6: 1115-6.

${ }^{18}$ Medical Statistics of births, 1974, 1977, and 1979, Copenhagen: National Health Service.

${ }^{19}$ Schumacher GH. Über einige Aspekte der experimentellen Teratologie. Anat Anz 1976; 140: $337-44$. 